\title{
Analisis Tata Kelola Teknologi Informasi Menggunakan Framework Cobit 5 (Studi Kasus: STIKES Garuda Putih Jambi)
}

\author{
Samsinar ${ }^{1, *}$, Rudolf Sinaga $^{2}$, Renny Afriany $^{1}$ \\ ${ }^{1}$ Program Studi D-3 Keperawatan, STIKES Garuda Putih, Jambi, Indonesia \\ ${ }^{2}$ Fakultas Ilmu Komputer, Program Studi Sistem Informasi, Universitas Dinamika Bangsa, Jambi, Indonesia \\ Email: 1, ${ }^{*}$ samsinarrr@gmail.com, ${ }^{2}$ rudolfverdinan@gmail.com, ${ }^{3}$ reniafriani.44@gmail.com \\ Email Penulis Korespondensi: samsinarrr@gmail.com
}

\begin{abstract}
Abstrak-Implementasi TI memerlukan mekanisme tata kelola TI yang baik untuk melakukan pengawasan secara menyeluruh agar tujuan bisnis suatu organisasi benar-benar dapat dicapai secara efektif dan efisien. Semua level pengelola IT harus memahami bahwa risiko adalah hal yang tidak pasti dan mempunyai dampak negatif terhadap suatu tujuan yang hendak dicapai. Risiko dapat menjadi tantangan besar bagi setiap organisasi atau institusi yang harus mampu melakukan manajemen risiko dengan sebaik-baiknya. Dengan adanya manajemen risiko yang dikelola dengan baik, maka akan dapat melindungi aset TI dan menambah nilai pengelolaan TI yang dimiliki. STIKES Garuda Putih adalah salah satu organisasi nirlaba yang bergerak dibidang pendidikan kesehatan. Untuk menjamin layanan yang prima bagi seluruh civitas maupun stackholder berkaitan terhadap layanan TI, maka diperlukan kegiatan analisis tata kelola TI untuk melihat apakah sudah berjalan dengan baik. Kegiatan analisis tersebut akan dilakukan dengan menggunakan kerangka COBIT 5. Dalam penelitian ini model kapabilitas sebagai alat ukur terhadap jawaban responden dari kuesioner dibuat berdasarkan framework cobit 5 . Berdasarkan hasil analisis tingkat kematangan proses terhadap tata kelola TI STIKES Garuda Putih, didapatkan rata-rata nilai kematangan (capability) berada di 3,6 dengan nilai gap 1,4, sehingga disimpulkan bahwa Tata Kelola TI telah dilaksanakan namun masih terdapat domain yang harus diperbaiki dan ditingkatkan agar mencapai level maksimal. Direkomendasikan perlu dibuatnya SOP dan laporan pencapaian tata kelola kinerja TI, penanggulangan resiko TI, peningkatan manajemen strategi TI dan perlu adanya struktur pengendalian internal tata kelola TI.
\end{abstract}

Kata Kunci: IT Governance; Manajemen IT; Proces Capability; Cobit 5; STIKES Garuda Puth

Abstract-The implementation of IT requires good IT governance mechanisms to conduct comprehensive oversight so that the business goals of an organization can truly be achieved effectively and efficiently. All levels of IT managers must understand that risk is uncertain and harms a goal to be achieved. Risk can be a big challenge for any organization or institution that must be able to perform risk management as best it can. With well-managed risk management, it will be able to protect IT assets and add value to IT management. STIKES Garuda Putih is one of the nonprofit organizations that operate in the field of health education. To ensure excellent service for all communities and stakeholders related to IT services, it is necessary to conduct IT governance analysis activities to see if it is working properly. The analysis activity will be done using the COBIT framework 5. In this study, the capability model as a measuring tool for respondents' answers from the questionnaire is made based on the cobit framework 5. Based on the results of the process maturity level analysis on IT management (capability) is in the 3.6 to 1.4 the gap, so that concluded that IT governance has been implemented, but there is still the domain must be improved to achieve the maximum level. It is recommended that SOPs and IT performance management achievement reports, IT risk management, IT management strategy improvement, and the need for an internal control structure of IT governance be established.

Keywords: IT Governance; IT Management; Process Capability; Cobit 5; STIKES Garuda Putih

\section{PENDAHULUAN}

Perkembangan Teknologi Informasi (TI) dan komunikasi telah menggeser kemampuan otot bahkan otak manusia diberbagai bidang ilmu maupun aktivitas manusia[1]. Sesuatu yang sudah tidak mungkin dipungkiri akan besarnya sumbangan dari teknologi informasi dan komunikasi bagi peradaban maupun kesejahteraan manusia [2][3]. Salah satu pengaruh yang bisa dirasakan seperti di dunia pendidikan yaitu dalam hal berbagi informasi, bagaimana insan pendidikan dapat mengakses informasi dunia dengan sangat cepat dan mudah, sehingga mereka bisa mendapatkan literasi tentang perkembangan berbagai macam ilmu pengetahuan bahkan perbandingan perkembangan ilmu pengetahuan dari setiap bidang. Suatu akses yang tentunya akan memperkaya para insan pendidikan dengan segudang informasi yang dapat memacu motivasi mereka untuk meningkatkan kreativitasnya, sesuai bidang ilmu yang ditekuni bahkan membantu aktivitas dalam hal pengambilan keputusan.

Namun, disisi lain bahwa implementasi teknologi informasi sendiri membutuhkan investasi yang besar serta resiko yang tinggi[4]. Implementasi TI memerlukan mekanisme tata kelola TI yang baik untuk melakukan pengawasan secara menyeluruh agar tujuan bisnis suatu organisasi benar-benar dapat dicapai secara efektif dan efisien [5]. Kita harus memahami bahwa risiko adalah hal yang tidak pasti dan mempunyai dampak negatif terhadap suatu tujuan atau keinginan yang hendak dicapai. Risiko dapat menjadi tantangan besar bagi setiap organisasi atau institusi dimana mereka harus mampu melakukan manajemen risiko dengan sebaik-baiknya. Dengan adanya manajemen risiko yang dikelola dengan baik, maka mereka dapat melindungi nilai (protecting value) dan menambah nilai (creating value) yang akan menjadi kekuatan mereka [6][7][4].

STIKES Garuda Putih adalah salah satu organisasi nirlaba yang bergerak dibidang pendidikan kesehatan dengan memiliki beberapa sistem informasi. Adapun sistem informasi yang digunakan seperti Sistem Informasi Akademik, Digital Library, Open Journal System (OJS), Portal Website serta aplikasi-aplikasi terintegrasi 
Kemendikbud seperti aplikasi pelaporan PDDikti, SISTER, SIMDOS, PAK-Online dan aplikasi lainnya. Oleh karena aplikasi tersebut merupakan aplikasi yang sangat penting dalam mendukung manajemen dan layanan operasional institusi, sehingga perlu adanya jaminan agar akses dan ketersediaannya tetap dalam kondisi stabil. Namun dari hasil pengamatan dan wawancara yang dilakukan terhadap unit terkait, ditemukan bahwa masih seringnya terjadi permasalahan baik dari sisi tata kelola maupun dari sisi operasionalnya, seperti masih sering terjadi server down oleh karena adanya gangguan dari luar sistem, demikian juga dengan akses yang terkadang sangat lambat oleh karena overload penggunaan sistem yang disebabkan kapasitas bandwidth yang masih tergolong standar. Hal ini tentu akan memberi dampak buruk baik terhadap proses pengolahan data untuk semua sistem karena tidak sesuai lagi dengan standar layanan yang ditetapkan, bahkan berdampak buruk bagi perangkat keras yang digunakan karena dipaksa untuk menggunakan sumber daya yang jauh lebih besar sehingga akan menimbulkan biaya perawatan yang besar pula.

Untuk menjamin terciptanya layanan yang prima bagi seluruh civitas akademika diperlukan analisis terhadap tata kelola teknologi informasi yang saat ini digunakan. Oleh sebab itu pada penelitian ini, kegiatan analisis tersebut dilakukan untuk mengukur tingkat kematangan dan kemampuan tata kelola teknologi informasi, dan melihat apakah sudah berjalan dengan baik serta memberikan rekomendasi terhadap perbaikan tata kelola teknologi informasi pada institusi tersebut. Dalam penelitian ini, kegiatan analisis terhadap rangkaian tata kelola teknologi informasi tersebut akan dilakukan dengan menggunakan COBIT 5 (Control Objectives for Information and related Technology). Dalam cobit 5 tersedia hal-hal yang perlu dilakukan agar dapat mewujudkan visi misi suatu perusahaan [8][9].

Penelitian terdahulu yang mendukung penelitian ini berjudul 'Penerapan Framework Cobit 5 Pada Audit Tata kelola TI Di Dinas Komunikasi dan Informatika Kabupaten Oku yang hanya berfokus pada domain MEA 01,MEA 02,MEA 03.sedangkan penelitian yang kami lakukan tidak hanya focus pada domain MEA tapi juga merujuk pada domain DSS (Delivery Support System) sehingga tingkat kematangan menjadi lebih kuat untuk memberikan rekomendasi terhadap Tata Kelola TI [11].

Sedangkan pada penelitian berikutnya yang berjudul 'Analisis Tata Kelola TI Menggunakan Framework Cobit.5 Domain Deliver Support And Service (Studi Kasus: Yayasan Eka TJipta, Jakarta)’ yang hanya membahas domain DSS nya saja. Perbedaan dengan penelitian ini adalah dari segi pembahasan domain yang bukan hanya dari segi DSS tetapi juga pada domain APO dan BAI. Dengan adanya tambahan domain hasil rekomendasi mengenai tata kelola tentunya lebih jelas dan lebih terarah [7].

Sementara pada penelitian selanjutnya yang berjudul Analisis Tata Kelola TI Menggunakan Kerangka Kerja Cobit 5 (Studi Kasus Diskominfo Lombok Barat) yang menggunakan struktur cobit 5 pada domain APO nya saja, tidak terdapat domain BAI, DSS dan MEA. Sehingga hasil dari penelitian ini hanya terlihat bagian manajemen TI nya saja, belum terdapat domain MEA yang berfungsi untuk melihat identifikasi keberhasilan kinerja IT, monitoring dan evaluasi kinerja TI apakah sudah sesuai dengan tata kelola yang sudah diterapkan [4][12].

\section{METODOLOGI PENELITIAN}

\subsection{Tahapan Penelitian}

Tata kelola teknologi informasi adalah suatu cabang tata kelola perusahaan yang berfokus pada manajemen teknologi informasi dan resikonya. Tata kelola teknologi informasi menekankan agar teknologi informasi (TI) perusahaan selaras dengan tujuan bisnis perusahaan. Tata kelola teknologi informasi juga menguraikan bagaimana organisasi mengatur dan mengurus sumber daya TI dengan mempertimbangkan pengawasan serta pengendalian [10]. Sebagai kegiatan awal pada penelitian ini adalah melakukan observasi lingkungan penelitian, yang dilanjutkan dengan penyusunan kuesioner berdasarkan area penelitian, penentuan sampel penelitian, perolehan data, serta perhitungan nilai kematangan yang dianalisis menggunakan kerangka kerja Cobit 5. Cobit 5 dapat digunakan sebagai alat monitoring dan evaluasi tata kelola pada sebuah perusahaan karena memiliki domain yang lengkap untuk melihat sejauh mana kinerja TI dalam semua aspek.[11]

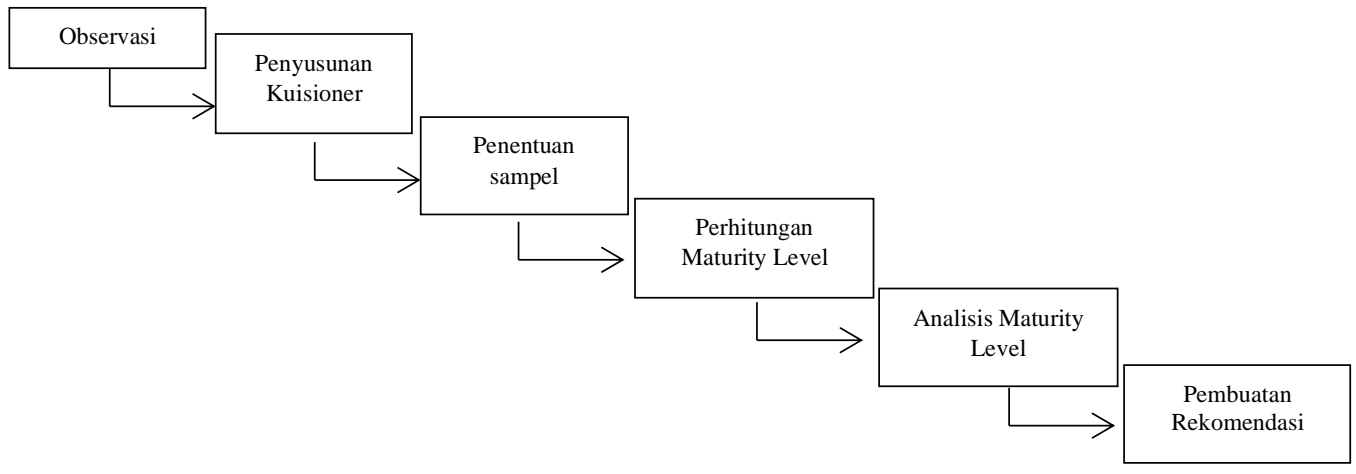

Gambar 1. Diagram Tahapan Penelitian 
JURNAL MEDIA INFORMATIKA BUDIDARMA

Volume 5, Nomor 1, Januari 2021, Page 138-148

ISSN 2614-5278 (media cetak), ISSN 2548-8368 (media online)

Available Online at https://ejurnal.stmik-budidarma.ac.id/index.php/mib DOI 10.30865/mib.v5i1.2573

\subsection{COBIT 5}

COBIT 5 merupakan kerangka yang mengukur sejauh mana tingkat keberhasilan tiap proses dalam tata kelola dan manajemen system informasi selain itu juga dapat memanfaatkan sumberdaya secara optimal serta dapat mengontrol bagian mana saja yang perlu ditingkatkan performanya. Dalam hal ini Process Assessment Model (PAM) pada COBIT 5 memiliki dimensi yang namanya capability process. Menurut versi COBIT 5, model capability ini berdasarkan ISO/IEC 15504, standar yang mengatur Software Engineering dan Process Assessment. COBIT 5 dapat menghasilkan informasi yang saling berhubungan yang memperhatikan kepentingan TI mencakup stakeholder internal dan ekstenal.

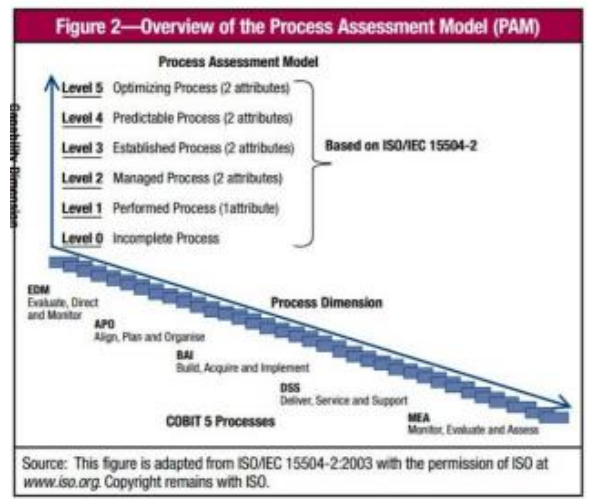

Gambar 2. Overview COBIT 5

Model proses Assessment terdiri dari 2 dimensi, seperti yang ditunjukkan pada gambar 2. Dalam satu dimensi, adalah dimensi pendifinisian dan dimensi yang lain merupakan dimensi pengklasifikasian. Model Penilaian Proses pengoptimalan Level 5 (2 atribut), Proses Prediksi Level 4 (2 atribut) ke dalam kategori proses. Di dimensi lain, file dimensi kapabilitas, sekumpulan atribut proses dikelompokkan ke dalam tingkat kemampuan yang ditentukan. Model proses Assessment ini memberikan karakteristik yang dapat mengukur level ketercpaian kinerja IT.

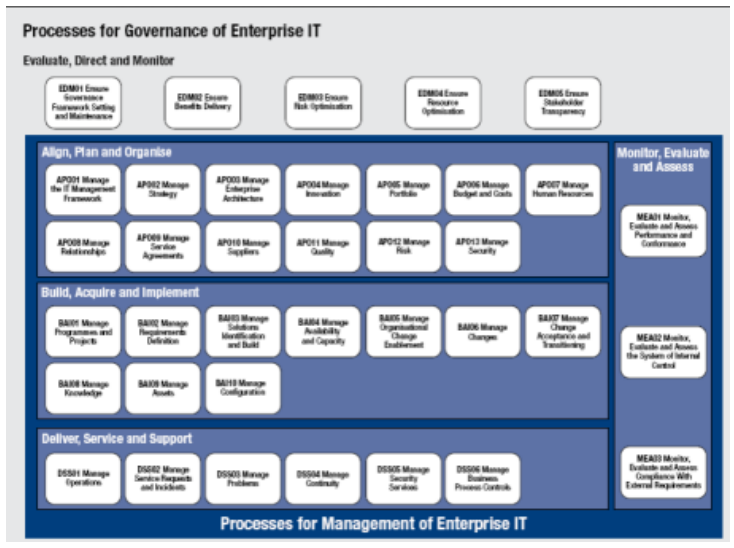

Gambar 3. Proses Tata Kelola dalam Cobit 5

Untuk mengetahui proses mana saja yang akan dianalisa sesuai dengan keadaan perusahaan, dalam COBIT 5 kita perlu melakukan pemetaan terlebih dahulu enterprise goals dan IT-related goals yang ada dalam perusahaan. Pemetaan dapat dilakukan setelah kita mengetahui tujuan bisnis perusahaan dan memetakannya terlebih dahulu dalam tujuan bisnis COBIT 5. Dalam penelitian ini menggunakan model kapabilitas sebagai alat ukur terhadap jawaban responden dari kuesioner yang dibuat berdasarkan framework cobit 5. Berikut adalah penjelasan secara umum tentang 5 domain COBIT (ISACA, 2014):[14][15]

a. Evaluate, Direct and Monitor (EDM), merupakan domain yang berbicara tentang penilaian dan evaluasi, pengarahan dan pengawasan, domain EDM memiliki 5 sub domain. Domain EDM ini berasal dari area governance of enterprise IT.

b. Align, Plan and Organize (APO), merupakan domain yang berbicara tentang penyelarasan, perencanaan dan pengolahan TI, domain APO memiliki 13 sub domain.Domain APO berasal dari management of enterprise IT.

c. Build, Acquire and Implement (BAI), merupakan domain pembangunan dan pengimplementasian TI, domain BAI memiliki 10 sub domain. Domain BAI berasal dari area management of enterprise IT. 


\section{JURNAL MEDIA INFORMATIKA BUDIDARMA}

Volume 5, Nomor 1, Januari 2021, Page 138-148

ISSN 2614-5278 (media cetak), ISSN 2548-8368 (media online)

Available Online at https://ejurnal.stmik-budidarma.ac.id/index.php/mib

DOI 10.30865/mib.v5i1.2573

d. Deliver, Service and Support (DSS), merupakan domain yang berbicara tentang pengiriman pemberian layanan dan support TI untuk perusahaan atau organisasi, domain ini memiliki 6 sub domain. Domain DSS berasal dari area management of enterprise IT.

e. Monitor, Evaluate and Assess (MEA), merupakan domain pengawasan, evaluasi dan proses pencobaan TI di perusahaan atau organisasi, domain ini memiliki 3 sub domain. Domain MEA berasal dari area management of enterprise IT.

Untuk mengetahui proses mana saja yang akan dianalisa sesuai dengan keadaan perusahaan, dalam COBIT 5 kita perlu melakukan pemetaan terlebih dahulu enterprise goals dan IT-related goals yang ada dalam perusahaan. Pemetaan dapat dilakukan setelah kita mengetahui tujuan bisnis perusahaan dan memetakannya terlebih dahulu dalam tujuan bisnis COBIT 5.

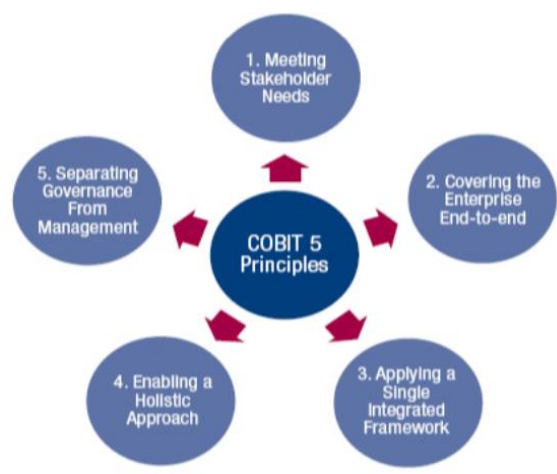

Gambar 4. Prinsip COBIT 5

Berikut penjelasan mengenai 5 prinsip COBIT 5 di atas:

a. Meeting Stakeholder Needs: COBIT 5 menyediakan semua proses yang dibutuhkan untuk membantu perusahaan memenuhi kebutuhan pemangku kepentingan dalam perusahaan lewat penggunaan TI.

b. Covering the Enterprise End-to-end: COBIT 5 mengintegrasikan tata kelola TI ke tata kelola perusahaan.

c. Applying a Single Framework: COBIT 5 dikenal sebagai framework tata kelola TI yang lengkap dan standart yang mencakup banyak framework tata kelola yang ada.

d. Enabling a Holistic Approach: COBIT 5 mempunyai beberapa enablers untuk membantu mengimplementasikan tata kelola yang mudah dipahami dan sistem manajemen TI perusahaan.

e. Separating Governance from Management: COBIT 5 jelas sekali membedakan antara tata kelola dan manajemen. 2 hal tersebut mengarah pada aktivitas yang berbeda, membutuhkan struktur organisasi yang beda dan memiliki fungsi yang berbeda.

COBIT 5 menganjurkan bahwa organisasi menerapkan proses tata kelola(Governance) dan manajemen secara terpisah, seperti yang ditunjukkan gambar 4 dibwah ini.. Governance terdiri atas lima domain dalam proses evaluate, direct, and monitor (EDM) sedangkan Management terdiri atas 4 domain utama yang bertanggung jawab pada area Plan, Build, Run, and Monitor. Domain-domain pada area manajemen COBIT 5 merupakan perkembangan dari Cobit 4 ke Cobit 5. Bisa disimpulkan bahwa COBIT 5 memiliki 2 area kerja utama yang dipisahkan antara management dan governance. Terdapat 5 domain utama dalam 2 area kerja COBIT 5 yaitu :

a. Governance of Enterprise IT (Evaluate, Direct and Monitor (EDM)

b. Management of Enterprise IT (Align, Plan, and Organise (APO), Build, Acquire, and Implement (BAI), Deliver, Service, and Support (DSS), Monitor,Evaluate, and Assess (MEA)

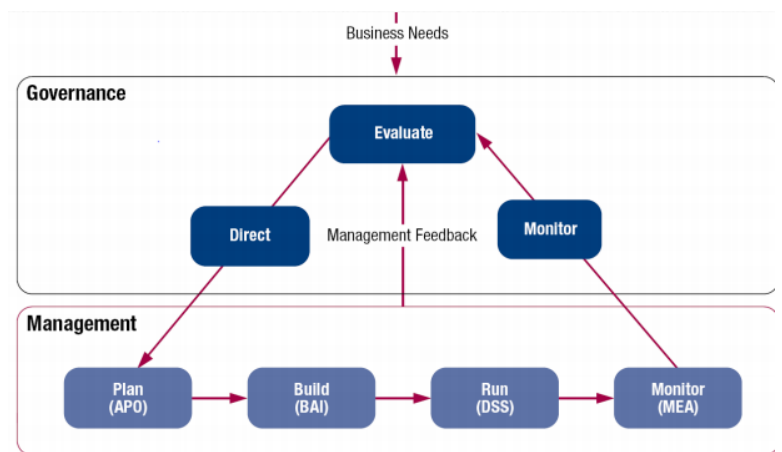

Gambar 5. Domain Pada COBIT 5 


\section{HASIL DAN PEMBAHASAN}

\subsection{Observasi Lingkungan Penelitian}

Proses observasi lingkungan dengan cara melakukan wawancara yang bertujuan mendapatkan informasi lebih lengkap mengenai masalah yang diteliti dan mengamati secara langsung kegiatan di tempat penelitian, untuk mendapatkan gambaran yang relevan dengan masalah dan tujuan penelitian. Hail dari wawancara yang dilakukan terhadap unit terkait, ditemukan bahwa masih seringnya terjadi permasalahan baik dari sisi tata kelola maupun dari sisi operasionalnya, seperti masih sering terjadi server down oleh karena adanya gangguan dari luar sistem, demikian juga dengan akses yang sangat lama oleh karena overload penggunaan sistem yang disebabkan kapasitas bandwidth yang masih tergolong standar.

\subsection{Penyusunan Kuisioner}

Kuesioner dibuat denga1n pernyataan dan jawaban kuesioner yang komunikatif sehingga mudah dimengerti oleh responden, Agar dapat memproleh data maka disusunlah kuesioner dengan mengikuti panduan Cobit 5 yang mengambil setiap proses pada domain cobit untuk dijadikan butir-butir pertanyaan. Dalam kuisioner tingkat persetujuan skala 1 sampai dengan 5, yaitu tidak ada, ada ,ada belum lengkap, lengkap dan sangat lengkap. Total pernyataan yaitu 21 yang terdiri dari 5 pernyataan pada domain APO 01, 5 pernyataan pada domain BAI 01, 7 pernyataan pada domain DSS 01 dan 4 pernyataan pada domain MEA 01. COBIT 5 memiliki 5 Domain yang terbagi atas 37 proses TI dimana nantinya akan dianalisa sesuai dengan kebutuhan penelitian yaitu yang mewakili tentang Tata Kelola Teknologi Informasi, setelah dianalisa sesuai dengan kebutuhan didapatkanlah butir-butir pernyataan seperti pada table dibawah ini:[15]

Tabel 1. Pernyataan Kuesioner

\begin{tabular}{|c|c|c|}
\hline Domain & Indikator & Kode \\
\hline \multirow{5}{*}{ APO 01} & \multirow{5}{*}{$\begin{array}{l}\text { Rencana strategis IT, Organisasi, } \\
\text { tujuan manajemen, Penglolaan } \\
\text { SDM, dan Pengaturan Resiko IT }\end{array}$} & APO 01 \\
\hline & & APO 02 \\
\hline & & APO 03 \\
\hline & & APO 04 \\
\hline & & APO 05 \\
\hline \multirow{5}{*}{ BAI 01} & \multirow{5}{*}{$\begin{array}{l}\text { Maintenance Software dan } \\
\text { Infastruktur TI, Pengadaan Sumber } \\
\text { daya TI, Update Data Base }\end{array}$} & BAI 01 \\
\hline & & BAI 02 \\
\hline & & BAI 03 \\
\hline & & BAI 04 \\
\hline & & BAI 05 \\
\hline \multirow{7}{*}{ DSS 01} & \multirow{7}{*}{$\begin{array}{l}\text { Pelayanan ke Stakeholder, } \\
\text { kinerja dan kapasitas TI, } \\
\text { ketersediaan layanan lanjutan, } \\
\text { security TI, } \\
\text { Pengelolaan data } \\
\text {, Fasilitas, } \\
\text { dan user }\end{array}$} & DSS 01 \\
\hline & & DSS02 \\
\hline & & DSS 03 \\
\hline & & DSS 04 \\
\hline & & DSS 05 \\
\hline & & DSS 06 \\
\hline & & DSS 07 \\
\hline \multirow{4}{*}{ MEA 01} & \multirow{4}{*}{$\begin{array}{l}\text { Monitoring dan evaluasi } \\
\text { keberhasilan kinerja IT, penyediaan } \\
\text { tata kelola TI }\end{array}$} & MEA 01 \\
\hline & & MEA 02 \\
\hline & & MEA 03 \\
\hline & & MEA 04 \\
\hline
\end{tabular}

Tabel diatas menunjukkan domain-domain yang digunakan dalam menyusun kuesioner dengan berpedoman pada framework cobit 5 yaitu dengan melihat point-point aktivitas pada setiap domain untuk menentukan nilai maturity. Komponen yang digunakan adalah domain APO 01 merupakan domain yang berbicara tentang penyelarasan, perencanaan dan pengolahan TI dengan indikator rencana strategis IT, organisasi , tujuan manajemen, penglolaan SDM, dan pengaturan resiko IT. Domain BAI 01 merupakan domain pembangunan dan pengimplementasian TI dengan indikator maintenance software dan infastruktur TI, pengadaan sumber daya TI, dan update database. Domain DSS 01 merupakan domain yang berbicara tentang pengiriman pemberian layanan dan support TI untuk perusahaan atau organisasi dengan indikator pelayanan ke stakeholder, kinerja dan kapasitas TI, ketersediaan layanan lanjutan, security TI, pengelolaan data dan, Fasilitas. Domain MEA merupakan domain pengawasan, evaluasi dan proses pencobaan TI di perusahaan atau organisasi dengan indikator monitoring dan evaluasi keberhasilan kinerja IT, dan penyediaan tata kelola TI. Setelah kuesioner disusun sesuai dengan panduan Cobit 5 dan sudah sesuai dengan tujuan penelitian selanjutnya didistribusikan. Data yang diperoleh merupakan data primer atau data yang diperoleh langsung dari hasil pengisian kuesioner oleh responden. 


\subsection{Penetuan Sampel Penelitian}

Untuk memperoleh sampel dari populasi yang ada digunakan model RACI (Responsibility, Accountability, Consult and Informed), berikut penjelasan untuk tiap bagian [13]

a. $\mathrm{R}$ (Responsible), adalah bagian yang melakukan suatu kegiatan atau bertanggung jawab dalam menyelesaikan suatu aktifitas.

b. A (Accountable), adalah pihak yang memiliki wewenang memutuskan suatu kebijakan dan mengarahkan jalannya pelaksanaan aktivitas.

c. C (Consulted), adalah pihak yang berkontribusi akan sebuah kegiatan yang menjadi tempat konsultasi dalam pelaksanaan aktivitas.

d. I (Informed), adalah pihak yang perlu mengetahui hasil dari suatu kebijakan yang akan diberikan informasi mengenai pelaksanaan aktivitas.

Sampel yang akan memberikan informasi terkait teknologi informasi yang digunakan di STIKES Garuda Putih Jambi yang dibuat didasarkan pada kerangka Cobit.5, berikut daftar responden berdasarkan RACI dapat dilihat pada table 2 .

Tabel 2. Tabel RACI

\begin{tabular}{lc}
\hline \multicolumn{1}{c}{ Fungsional Cobit } & Fungsional Organisasi \\
\hline Head Of IT Operation & Ka.TSI \\
Head Of IT Development & Ka.TSI \\
Head Of IT Administration & Staf TSI \\
Bisnis Executive & Waket 1 \\
Pelaksana (Administration) & BAAK \\
\hline
\end{tabular}

\subsection{Perhitungan Nilai Kematangan (Proses Capability Level)}

Proses Capability Level merupakan sebuah titik pada skala ordinal 6 point (kemampuan proses) pada setiap level yang mewakili kemampuan dari setiap proses tersebut. Maturity level diperoleh dengan menghitung setiap jawaban yang diberikan oleh responden dikalikan dengan setiap jawaban yang diberikan oleh responden dikalikan dengan setiap jawaban yang telah ditentukan kemudian dibagikan dengan total pertanyaan.

$$
\text { Nilai Maturity }=\frac{\sum(\text { Jawaban } x \text { Bobot })}{\sum \text { Pertanyaan }}
$$

Dalam COBIT 5 penilaian kematangan tata kelola TI menggunakan Capability Model. Jumlah level penilaian ini terbagi dalam enam level, berikut penjelasan level dari Process Capability (ISACA, 2014): [14][15]

1) Level 0 Incomplete Process Proses tidak dilaksanakan atau gagal untuk mencapai tujuan prosesnya. Pada level ini, ada sedikit atau tidak ada sama sekali bukti dari setiap pencapaian tujuan proses.

2) Level 1 Performed Process Proses diimplementasikan untuk mencapai tujuan bisnisnya.

3) Level 2 Managed Process Proses yang diimplementasikan dikelola (planned, monitored and adjusted) dan hasilnya ditetapkan dan dikontrol.

4) Level 3 Established Process Proses didokumentasikan dan dikomunikasikan (untuk efisiensi organisasi).

5) Level 4 Predictable Process Proses dimonitor, diukur dan diprediksi untuk mencapai hasil.

6) Level 5 Optimizing Process Proses diprediksikan kemudian ditingkatkan untuk memenuhi tujuan bisnis yang relevan dan nantinya akan relevan dengan tujuan bisnis yang akan datang.

Berdasarkan hasil kuesioner yang dibagikan, skala penilaian kuesioner yaitu mulai dari 1 sampai 5 , disertai dengan penjelasan masing-masing skala sehingga responden dapat menentukan jawaban yang diberikan dengan mudah. Berikut adalah hasil pengolahan kuesioner sehingga didapat Maturity level yang diperoleh dengan menghitung setiap jawaban yang diberikan dikalikan dengan setiap jawaban yang diberikan yang telah ditentukan kemudian dibagikan dengan total pertanyaan.

Tabel 3. Maturity Level Pada Domain APO 01

\begin{tabular}{cccc}
\hline & Kode & $\begin{array}{c}\text { Nilai } \\
\text { Maturity }\end{array}$ & Level \\
\hline 1 & APO 01 & 3.2 & 3 \\
2 & APO 02 & 3.8 & 4 \\
3 & APO 03 & 4 & 4 \\
4 & APO 04 & 4.2 & 4 \\
5 & APO 05 & 2.8 & 3 \\
\multicolumn{2}{c}{ Rata-rata } & 3.6 & 3.6 \\
\hline
\end{tabular}


JURNAL MEDIA INFORMATIKA BUDIDARMA

Volume 5, Nomor 1, Januari 2021, Page 138-148

ISSN 2614-5278 (media cetak), ISSN 2548-8368 (media online)

Available Online at https://ejurnal.stmik-budidarma.ac.id/index.php/mib DOI 10.30865/mib.v5i1.2573

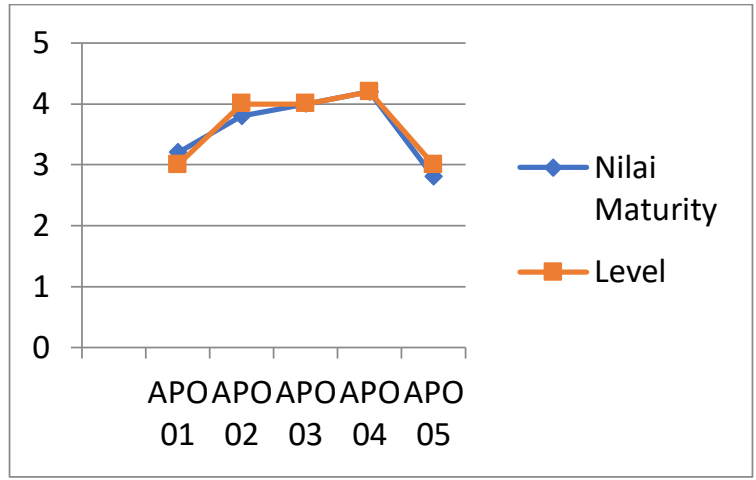

Gambar 6. Grafik Maturity Level Domain APO

Pada domain APO 01 nilai rata-rata maturity level yaitu 3.6 yang berada pada level 3.6 yang dibulatkan menjadi 4, level 4 ini menunjukkan bahwa pada domain APO 01 berada pada level Predictable Process artinya Proses sudah dimonitor, dapat diukur dan diprediksi untuk mencapai hasil.

Tabel 4. Maturity Level Pada Domain BAI 01

\begin{tabular}{cccc}
\hline No & Kode & $\begin{array}{c}\text { Nilai } \\
\text { Maturity }\end{array}$ & Level \\
\hline 1 & BAI 01 & 3 & 3 \\
2 & BAI 02 & 4 & 4 \\
3 & BAI 03 & 3.8 & 4 \\
4 & BAI 04 & 4 & 4 \\
5 & BAI 05 & 3.8 & 4 \\
& Rata-rata & 3.72 & 3.82 \\
\hline
\end{tabular}

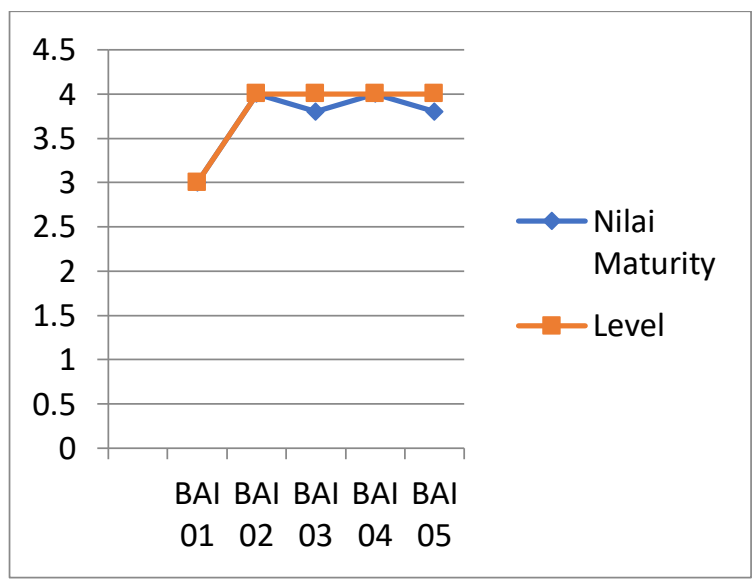

Gambar 7. Grafik Maturity Level Domain BAI 01

Hasil dari kuesioner menunjukkan bahwa rata-rata nilai maturity pada domain BAI 01 adalah 3.72 yang berada juga pada level 4 , level 4 ini menunjukkan bahwa pada domain APO 01 berada pada level Predictable Process artinya Proses sudah dimonitor, dapat diukur dan diprediksi untuk mencapai hasil.

Tabel 5. Maturity Level Pada Domain DSS 01

\begin{tabular}{lccc}
\hline No & Kode & $\begin{array}{c}\text { Nilai } \\
\text { Maturity }\end{array}$ & Level \\
\hline 1 & DSS 01 & 3 & 3 \\
2 & DSS02 & 3.6 & 4 \\
3 & DSS 03 & 4 & 4 \\
4 & DSS 04 & 4 & 4 \\
5 & DSS 05 & 4 & 4 \\
6 & DSS 06 & 4.2 & 4 \\
7 & DSS 07 & 4.4 & 4 \\
Rata-rata & & 3.9 & 3.7 \\
\hline
\end{tabular}




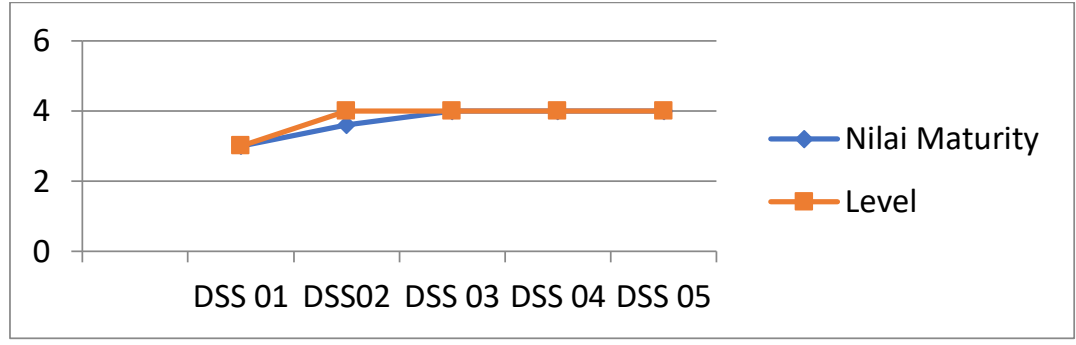

Gambar 8. Grafik Maturity Level Domain DSS

Nilai maturity yang dihasilkan pada domain DSS yaitu dengan rata-rata 3.9 yang berada dilevel 4.

Tabel 6. Maturity Level Pada Domain MEA 01

\begin{tabular}{llcc}
\hline No & Kode & $\begin{array}{l}\text { Nilai } \\
\text { Maturity }\end{array}$ & Level \\
\hline 1 & MEA 01 & 3.4 & 3 \\
2 & MEA 02 & 3 & 3 \\
3 & MEA 03 & 3.4 & 3 \\
4 & MEA 04 & 3.4 & 3 \\
Rata-rata & & 3.1 & 3 \\
\hline
\end{tabular}

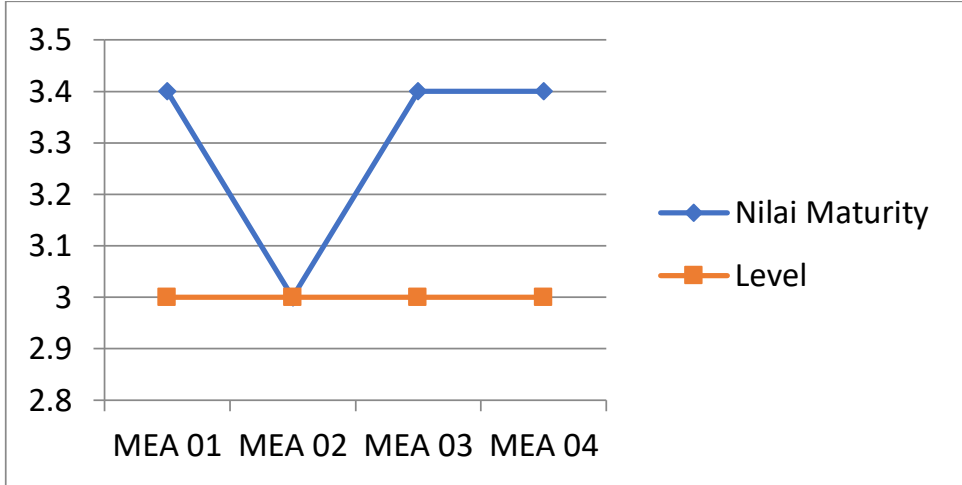

Gambar 9. Grafik Maturity Level Domain MEA

Pada domain MEA 01 didapatkan hasil maturity level dengan rata-rata 3 dan berada pada level 3. Level 3 menunjukkan Established Process yaitu Proses didokumentasikan dan dikomunikasikan (untuk efisiensi organisasi) tetapi belum secara maksimal atau belum lengkap

\subsection{Analisis Nilai Kematangan}

Penilaian tingkat kematangan saat ini dan tingkat kematangan yang diharapkan yang telah ditentukan oleh RACI Chart sebelumnya maka selanjutnya analisis gap atau kesenjangan. Indikator keberhasilan adalah kemampuan proses dalam meraih tingkat keberhasilan yang ditentukan oleh atribut. Hasil yang akan dicapai diklasifikasikan dalam 4 kategori sebagai berikut: [14][15]

1. N (Not achieved/tidak tercapai), menunjukkan bahwa tidak ada atau pencapaian proses hanya sedikit yang diraih. Range pada kategori ini adalah $0-15 \%$

2. $\mathrm{P}$ (Partially achieved/tercapai sebagian), menunjukkan bahwa ada beberapa bukti proses pendekatan dan beberapa pencapaian atribut yang diraih. Range pada kategori ini adalah 15 - $50 \%$

3. L (Largely achieved/secara garis besar tercapai), menunjukkan bahwa pencapaian yang signifikan dalam sebuah proses , namun masih ada kelemahan sedikit kelemahan. Range pada kategori ini adalah 50 - $85 \%$

4. F (Fully achieved/tercapai penuh), menunjukkan bahwa proses sebuah atribut sudah lengkap dan pencapaiannya sudah sempurna. Tidak terdapat kelemahan dalam proses atribut tersebut. Range pada kategori ini adalah $85-100 \%$

Setelah maturity level dihasilkan , selanjutnya menentukan level dari tiap-tiap domain, dari level tersebut dapat dilihat proses berada dilevel mana, kemudian ditentukan harapan atau level yang diharapkan kemudian menentukan analisis gap atau kesenjangan. 
JURNAL MEDIA INFORMATIKA BUDIDARMA

Volume 5, Nomor 1, Januari 2021, Page 138-148

ISSN 2614-5278 (media cetak), ISSN 2548-8368 (media online)

Available Online at https://ejurnal.stmik-budidarma.ac.id/index.php/mib

DOI 10.30865/mib.v5i1.2573

Perhitungan target nilai kematangan tata kelola teknologi informasi STIKES Garuda Putih dari seluruh proses evaluasi yang telah ditentukan diperoleh beberapa kesenjangan atau GAP yang merupakan selisih dari nilai maturity (level) yang berjalan dengan nilai maturity (level) yang diharapkan.

Tabel 7. Nilai GAP/Kesenjangan

\begin{tabular}{|c|c|c|c|}
\hline Kode & Level & Harapan & GAP \\
\hline \multirow{6}{*}{ APO } & 3 & 5 & 2 \\
\hline & 4 & 5 & 1 \\
\hline & 4 & 5 & 1 \\
\hline & 4 & 5 & 1 \\
\hline & 3 & 5 & 2 \\
\hline & Rata-rata & & 1.4 \\
\hline \multirow{5}{*}{ BAI } & 3 & 5 & 2 \\
\hline & 4 & 5 & 1 \\
\hline & 4 & 5 & 1 \\
\hline & 4 & 5 & 1 \\
\hline & 4 & 5 & 1 \\
\hline & Rata-rata & & 1.2 \\
\hline \multirow{8}{*}{ DSS } & 3 & 5 & 2 \\
\hline & 4 & 5 & 1 \\
\hline & 4 & 5 & 1 \\
\hline & 4 & 5 & 1 \\
\hline & 3 & 5 & 2 \\
\hline & 4 & 5 & 1 \\
\hline & 4 & 5 & 1 \\
\hline & Rata-rata & & 1.3 \\
\hline \multirow{5}{*}{ MEA } & 3 & 5 & 2 \\
\hline & 3 & 5 & 2 \\
\hline & 3 & 5 & 2 \\
\hline & 3 & 5 & 2 \\
\hline & Rata-rata & & 1,4 \\
\hline
\end{tabular}

Hasil perhitungan maturity level dari tata kelola TI STIKES Garuda Putih telah diperoleh rata-rata sebesar 3,5 dengan rata-rata nilai gap sebesar 1,4 yang akan diperhitungkan dalam mencapai target harapan. Berikut adalah rekomendasi umum yang disusun berdasarkan kondisi tata kelola TI STIKES Garuda Putih:

a. Dari hasil dari perhitungan kuesioner diperoleh nilai kesenjangan (GAP) pada domain APO 01 yaitu 1.4 dengan target capaian pada level 5, sehingga secara kategori level mencapai $72 \%$ berada pada level L (Largely achieved/secara garis besar tercapai) namun masih perlu perbaikan dari penilaian dan pengaturan resiko IT sebagai implementasi. Hal ini menunjukkan belum adanya laporan penilaian target pencapaian tata kelola IT dan penanggulangan resiko IT.

b. Hasil perhitungan kuesioner diperoleh rata-rata nilai kesenjangan (GAP) pada domain BAI 01 yaitu 1.2 dengan target level 5, secara kategori level mencapai $76 \%$ yang menunjukkan kategori level L(largely achieved) pencapaian yang signifikan meski masih ada proses yang harus diperbaiki. Dilihat dari hasil kuesioner masih kurangnya pemeliharaaan aplikasi maka dari itu perlu adanya SOP perawatan perangkat IT yang dilakukan secara berkala.

c. Rata-rata nilai kesenjangan (GAP) yang diperoleh dari hasil perhitungan kuesioner pada domain DSS 01 yaitu 1.3 dengan target level 5, secara kategori mencapai $74 \%$ yang menunjukkan capaian berada pada level L (Largely achieved), target belum maksimal perlu diadakan perbaikan tata kelola dalam hal pengaturan kinerja IT dan perbaikan kapasitas kinerja IT.

d. Rata-rata nilai kesenjangan (GAP) pada domain MEA 01 yang diperoleh dari perhitungan kuesioner yaitu 2 dengan target 5,dengan keberhasilan system masih $60 \%$. Hal ini menunjukkan masih kurangnya tata kelola dari segi identifikasi, kinerja TI untuk itu perlu dibuatkan laporan monitoring dan evaluasi capaian kinerja IT dan system pengendalian internal serta penyediaan untuk tata kelola IT

\subsection{Rekomendasi}

Berdasarkan hasil pengolahan data dan temuan dari wawancara dan kuisioner, maka diperoleh rekomendasi untuk perbaikan TI kedepannya. Berikut table rekomendasi yang diperoleh. 
Tabel 8. Tabel Rekomendasi

\begin{tabular}{cl}
\hline Proses & \multicolumn{1}{c}{ Rekomendasi } \\
\hline APO 01 & $\begin{array}{l}\text { Dibuatkan rencana strategis TI, menetapkan SOP proses TI, dibuatkan pedoman tujuan } \\
\text { dan manajemen TI untuk jadi panduan kedepannya. Dibuatkan pedoman pengelolaan } \\
\text { sumber daya manusia yang berada pada divisi TI, dan laporan keberhasilan kinerja IT } \\
\text { dan penanggulangan resikon IT. }\end{array}$ \\
\hline BAI 01 & $\begin{array}{l}\text { Dibuatkan SOP maintenance perangkat TI minimal 2 kali dalam setahun atau } \\
\text { persemester, membuat metode yang optimal dalam melakukan monitoring fasilitas TI. } \\
\text { Pengecekan fasilitas bukan hanya dilakukan ketika ada gangguan misalnya server } \\
\text { down sehingga mengurangi resiko kegagalan akses . }\end{array}$ \\
\hline DSS 01 & $\begin{array}{l}\text { Pengaturan layanan dengan pihak ketiga belum maksimal ,sehingga diharapkan } \\
\text { kerjasama yang sudah ada dapat dikembangkan selain pembuatan system informasi } \\
\text { juga diadakan pelatihan secara berkala untuk divisi IT agar penggunakaan IT lebih } \\
\text { dipahami. }\end{array}$ \\
\hline MEA 01 & $\begin{array}{l}\text { Dilakukan monitoring dan controlling capaian kinerja TI, Adanya pelaporan kinerja } \\
\text { dan capaian kinerja TI sehingga diperoleh persentasi capaian kinerja apa saja yang } \\
\text { sudah tercapai dan yang belum tercapai untuk dilakukan perbaikan kinerja pada proses } \\
\text { selanjutnya. }\end{array}$ \\
\hline
\end{tabular}

\section{KESIMPULAN}

Berdasarkan hasil analisis tingkat kematangan proses yang dilakukan dengan menggunakan framework Cobit.5 terhadap tata kelola TI STIKES Garuda Putih, didapatkan rata-rata nilai kematangan (capability) berada di 3,6 dengan nilai gap 1,4, sehingga disimpulkan bahwa Tata Kelola TI pada STIKES Garuda Putih telah dilaksanakan namun masih terdapat domain yang harus diperbaiki dan ditingkatkan agar mencapai level maksimal. Direkomendasikan untuk kedepannya, perlu dibuat SOP, pedoman pelaksanaaan dan laporan pencapaian tata kelola kinerja IT, penanggulangan resiko IT, peningkatan pada manajemen strategi IT dan perlu adanya struktur pengendalian internal serta penyediaan tata kelola IT, dibuatkan monitoring dan evaluasi capaian kinerja IT pada tia-tiap divisi TI minimal 2 kali dalam satu tahun. Hasil laporan dipersentasikan tiap semesternya kemudian dijadikan acuan untuk meningkatkan tata kelola TI untuk kedepannya.

\section{UCAPAN TERIMAKASIH}

Terima kasih kepada pihak-pihak yang telah mendukung terlaksananya penelitian ini. Dukungan dan kerja sama yang baik dari divisi TSI (teknologi Sistem Informasi ) STIKES Garuda Putih yang antusias dalam pengisian kuesioner, wawancara serta bersedia menyediakan waktunya dalam berbagi informasi mengenai Tata Kelola TI yang diterapkan pada STIKES Garuda Puth. Terimakasih kepada seluruh tim redaksi Media Informatika Budidarma yang telah membantu dan mengarahkan hingga terbitnya artikel ini.

\section{REFERENCES}

[1] R. Umar, I. Riadi, and E. Handoyo, "Analisis Keamanan Sistem Informasi Berdasarkan Framework COBIT 5 Menggunakan Capability Maturity Model Integration (CMMI)," J. Sist. Inf. Bisnis, vol. 9, no. 1, p. 47, 2019, doi: 10.21456/vol9iss1pp47-54.

[2] T. Rahayu, N. Matondang, and B. Hananto, "Audit Sistem Informasi Akademik Menggunakan Metode COBIT 5 ( Studi Kasus UPN Veteran Jakarta ) Metode Pengumpulan Data Alur Penelitian Metode Analisis Data," J. Teknol. Inf. dan Pendidik., vol. 13, no. 305, 2020.

[3] R. E. Putri, "Penilaian Kapabilitas Proses Tata Kelola TI Berdasarkan Proses DSS01 Pada Framework COBIT 5," J. CoreIT, Vol.2, No.1, Juni 2016, 2016.

[4] I. P. Rahayu and N. Agitha, "Analisis Tata Kelola Teknologi Informasi Menggunakan Kerangka Kerja COBIT 5 (studi Kasus : DISKOMINFO Lombok Barat)," J. Teknol. Informasi, Komputer, dan Apl. (JTIKA ), vol. 1, no. 2, pp. 131140, 2019, doi: 10.29303/jtika.v1i2.23.

[5] A. Hakim, H. Saragih, and A. Suharto, "Jurnal Sistem Informasi ( Journal of Information Systems ). 2 / 10 ( 2014 ), 83 86 DOI : http://dx.doi.org/10.21609/jsi.v10i2.390,” J. Sist. Inf., vol. 10, no. 2, pp. 83-86, 2014.

[6] Y. A. P. Pardjo, "Manajemen Risiko Perusahaan," Grow. Publ., 2017.

[7] A. Wiraniagara and F. Wijaya, "Analisis Tata Kelola Teknologi Informasi Menggunakan Framework Cobit 5 Domain Deliver Support and Service ( Studi Kasus : Yayasan Eka Tjipta , Jakarta )," Sebatik, vol. 5, pp. 663-671, 2019.

[8] A. Makmur and M. Haming, "Analisis Tata Kelola Teknologi Informasi Pada Terminal Petikemas Makassar Menggunakan Framework Cobit 5," CESJ Cent. Econ. Students ..., vol. 1, no. 1, pp. 56-65, 2018, [Online]. Available: https://mail.jurnal.fe.umi.ac.id/index.php/CESJ/article/view/66.

[9] M. Islamiah, "Tata kelola teknologi informasi (IT governance) menggunakan framework cobit 5: studi kasus Dewan Kehormatan Penyelenggara Pemilu (DKPP)," repository.uinjkt.ac.id, 2014.

[10] H. Hilmawan, O. D. Nurhayati, and I. P. Windasari, "Analisis Tata Kelola Teknologi Informasi menggunakan 
JURNAL MEDIA INFORMATIKA BUDIDARMA

Volume 5, Nomor 1, Januari 2021, Page 138-148

ISSN 2614-5278 (media cetak), ISSN 2548-8368 (media online)

Available Online at https://ejurnal.stmik-budidarma.ac.id/index.php/mib

DOI 10.30865/mib.v5i1.2573

Kerangka Kerja COBIT 5 pada AMIK JTC Semarang,” J. Teknol. dan Sist. Komput., vol. 3, no. 2, p. 247, 2015, doi: 10.14710/jtsiskom.3.2.2015.247-252.

[11] H. T. Sihotang and J. R. Sagala, "Penerapan Tata Kelola Teknologi Informasi Dan Komunikasi Pada Domain Align, Plan and Organise (Apo) Dan Monitor, Evaluate and Assess (Mea) Dengan Menggunakan Framework Cobit 5 Studi Kasus: Stmik Pelita Nusantara Medan,” J. Mantik Penusa Desember, vol. 18, no. 2, pp. 2088-3943, 2015.

[12] E. Ekowansyah, Y. H. Chrisnanto, and P. N. Sabrina, "Audit Sistem Informasi Akademik Menggunakan COBIT 5 di Universitas Jenderal Achmad Yani," Pros. Semin. Nas. Komput. dan Inform. 2017 (ISBN 978 - 602 - 60250 - 1 -2), vol. 2017, pp. 201-206, 2017, [Online]. Available: http://www.senaski.unikom.ac.id/prosiding-file/201-206 erdis ekowansyah dkk 6 hal.pdf.

[13] R. S. Sepita Sari, Syahril Rizal, "Penerapan FRAMEWORK COBIT 5 Pada Audit Tata Kelola Teknologi Informasi," no. April, p. 8, 2014.

[14] COBIT 5, "COBIT 5: Process Assessment Model (PAM)," Isaca, p. 144, 2013, [Online]. Available: https://drive.google.com/folderview?id=0B9yuuoKpwX3MczducjREdEhqdTA\&usp=sharing.

[15] ISACA, COBIT ® Process Assessment Model (PAM): Using COBIT ® 5. 2013. 